\title{
ANALYSIS OF SURFACE DEFECTS IN COMPOSITES USING DIGITAL IMAGE CORRELATION AND ACOUSTIC EMISSION
}

\author{
Jaroslav Začal ${ }^{1}$, Petr Dostál' ${ }^{1}$, Jakub Rozlivka ${ }^{1}$, Martin Brabec $^{2}$ \\ ${ }^{1}$ Department of Technology and Automobile Transport, Faculty of Agronomy, Mendel University in Brno, \\ Zemědělská 1, 61300 Brno, Czech Republic \\ ${ }^{2}$ Department of Wood Science, Faculty of Forestry and Wood Technology, Mendel University in Brno,Zemědělská3, \\ 61300 Brno, Czech Republic
}

To cite this article: ZAČAL JAROSLAV, DOSTÁL PETR, ROZLIVKA JAKUB, BRABEC MARTIN. 2018. Analysis of Surface Defects in Composites Using Digital Image Correlation and Acoustic Emission. Acta Universitatis Agriculturae et Silviculturae Mendelianae Brunensis, 66(5): 1217-1224.

To link to this article: https://doi.org/10.11118/actaun201866051217

\begin{abstract}
This work employs the acoustic emission (AE) method for material state monitoring. AE presents a non-destructive evaluation technique, which could be used for detection of microstructural changes in composite material. Work describes the process of acquisition of AE in tensile loading of carbon composite materials. In course of tensile stress, the composite was monitored with optical method, applying principles of digital image correction (DIC). Optical stereovision method enables calculation of field shift and field of proportional deformation at composite surface. The objective is analysis of damage in carbon composite materials and employ the methodology of AE signal processing for facilitation of early damage diagnostics and prediction of structural failure. For this purpose, the experimental setup was designed to obtain results from 50 nominally identical composite samples in tensile loading test. Force load applied on samples was synchronically recorded along with AE and image data. Experimental data were subsequently analysed in a way enabling the description of typical phenomena in course of every measurement. Results show that observation of AE sources could be employed in facilitation of early damage diagnostics and establishment of failure prognosis. It is about internal changes in composite material.
\end{abstract}

Keywords: acoustic emission, carbon fibre, non destructive testing

\section{INTRODUCTION}

Composite materials are matching up the traditional construction materials in their mechanical properties and are feasible in manufacturing of supporting elements in flight industry constructions. They are also suitable alternative for metals and other traditional materials (Schinner et al., 1996). Despite numerous advantages the composites compared to metallic materials are more prone to mechanical damage when subjected to external forces, e.g. tension, pressure or impact, which may lead to interlayer delamination
(Eherstein, 2009). In prolonged application of external load, the delamination spreads in interlayers, whose weakening leads to catastrophic failure of composite structure (Deapartment of Defense, 2002). Testing of mechanical properties of composite materials has an undisputable role in manufacturing quality control, product quality control and new material development.

Various methods are employed to obtain the material characteristics in mechanical load testing (Angelidis et al,, 2004; Schinner et al., 1996; 
Plotnikov and Winfree, 1999). Each of these methods provides specific partial results. For accurate assessment of overall material condition, only synthesis and evaluation of values obtained with diverse measurements provides the objective overview of material state (Abry et al., 2001).

In course of mechanical load application, it was found out that specific emission signals are generated in material, which could be employed for micro-fissure detection in internal structure of stressed composite materials. The interesting feature of these signals is a fact, that they emerge already in course of load application, which precedes the macroscopic damage of material and its structural failure. For diagnostics and monitoring of mechanically stressed materials it is possible to employ the above-mentioned method and apply the results in prediction of material structural failure. Acoustic emission above all provides information on location of newly emerged crack or defect in materials. AE signal processing thus allows accurate study of the emergent changes in material structure. Acoustic emission is an example of viable method which proved useful in numerous composite systems, including those which contain metallic, polymeric and ceramic matrices (Baker et al., 2015; Ono, 2005; Lu et al., 2011). It was demonstrated that in course of frequency analysis the generated AE signal courses provide an exact information about damage type categories (De Groot et al., 2011; Gutkin et al., 2011). De Groot (De Groot et al., 2011) and Gutkin (Gutkin et al., 2011) present interesting results, which correlate well with measured peak frequencies (frequencies of highest value in FFT spectrum) of generated $\mathrm{AE}$, and also with damage caused by fracture mechanisms.

\section{MATERIALS AND METHODS}

Each trial of composites in this work was conducted with HEXCELL material samples. For manufacturing of testing samples prepreg PAN carbon weave was used. Formation of polymer composite was conducted with prepregs based on epoxy matrix with labelling 8552 (see Tab. I)

In total 50 pieces of samples were manufactured (Tab. II). These plates were subsequently cut and formatted due to standard requirements (ČSN
EN ISO 527-4). Samples used in this work were perpendicular, polymer fibre composites reinforced with carbon fibre of $250 \mathrm{~mm}$ length. General principle is that perpendicular samples are required for characterization of composite materials, because "dog bone" shape is prone to break in area where the sample width changes (Angelidis et al., 2004). Clamps of testing machine transfer locally concentrated tension. To minimize this adverse effect the sample needs to be thoroughly tightened in clamps to eliminate shear load.

Basic equipment of testing lab is universal tearing machine Zwick Z050/TH 3A (Fig. 1), which is designed for application of external mechanical load onto tested material samples. Conditions of load application were using TestXpert 11.02 software (Zwick Roell AG). Samples were fixed into self-tightening clamps. Tension magnitude was measured with load sensor of $50 \mathrm{kN}$ capacity at constant quasi-static velocity $2 \mathrm{~mm} . \mathrm{min}^{-1}$ until the collapse of sample. Collapse was defined with significant drop in force along with visible signs of sample fragmentation.

\section{Measurement of deformations}

Shift and deformations in direction of load application were recorded with spot measurement conducted with conventional extensometers equipped with two coupled sensoric arms. Arms of sensor were set to $30 \mathrm{~mm}$ distance. Complete data on deformation were obtained using the optic system, which applies the digital image correlation (DIC) principles. Measurement system consists of two cameras CCD AVT Stingray Cooper F-504B (light sensor cell size $3.45 \mu \mathrm{m}$, resolution $2452 \times 2056$ pixels $=5 \mathrm{MPx}$ ) equipped with Pentax lenses C2514-M, Pentax Precision Co., Ltd., focal length $25 \mathrm{~mm}$ ) in stereovision (3D) configuration, as depicted in Fig. 1. The contrast between components of sample at tested surface was enhanced with two cold light sources SobrietyCube 360 (Sobriety s. r. o., Kuřim, Czech Republic) equipped with LED chips Luminus Phlatlight CSM-360.

For achieving the maximum spatial resolution of sampled surface, the picture window was located into area of interest (AOI), which encompasses the entire superficial area of sample $25 \times 150 \mathrm{~mm}$. Such picture window was obtained in measurement

I: Used prepreg material type

\begin{tabular}{cccc}
\hline Label & Binding & Mass $\left[\mathbf{g} / \mathbf{m}^{2}\right]$ & Fibre type \\
\hline GG 245T & Twill & 245 & HS 3K \\
GG 380T & Twill & 380 & HS 12K \\
\hline
\end{tabular}

II: Prepregtypes used in experiment

\begin{tabular}{ccccccc}
\hline Prepreg type & $\begin{array}{c}\text { Prepreglayer } \\
\text { count }\end{array}$ & Width [mm] & Length [mm] & $\begin{array}{c}\text { Thickness } \\
{[\mathrm{mm}]}\end{array}$ & $\begin{array}{c}\text { Fibre } \\
\text { orientation }\end{array}$ & Test set [pcs] \\
\hline GG 245T & 1 & 25 & 250 & 0.94 & {$\left[0^{\circ}, 90^{\circ}, 0^{\circ}, 90^{\circ}\right]$} & 50 \\
\hline GG 630T & 1 & & & & & \\
\hline
\end{tabular}


distance set to $504 \mathrm{~mm}$, with laser range-finder BOSH GLM 50 Professional. Cameras were placed onto a common arm in distance $733 \mathrm{~mm}$. Acquisition set was placed in a such position to align the image centre with AOI centre. Aperture $\mathrm{f} / 6$ was selected for obtaining the sufficient view depth to cover the entire AOI location outside of camera sensor plane. Described geometry of optical settings was calibrated with series of 30 left and right images of calibration grid with $5.5 \mathrm{~mm}$ mesh in various geometric orientations. Such optical coordination provides the conversion factor of $4.119 \mathrm{px} \mathrm{mm}^{-1}$.

Entire experimental data were obtained synchronically every 0.25 s $\quad\left(\begin{array}{llll}4 & \mathrm{~Hz}\end{array}\right)$ using the hardware trigger device. Selected interval was suitable with consideration to induced quasi-static velocity of load application as well as spot spectrum recognition with used software. Deformation fields were calculated from partial derivates of shift with Lagrange's notation in Vic-3D software v. 2010. Proportional deformations were calculated locally using the field of $3 \times 3$ points and size of deformation filter $5 \times 5$ points. Sizes of subset $25 \times 25$ pixel and subset step 5 pixel provided optimal ratio between the correlated point density ( 6 points $/ \mathrm{mm}^{-2}$ ) and robustness in image coupling. Accuracy of measurement was assessed on basis of shift field and proportional deformation found in 5 images with no load. Deformation in axial direction was determined with $0.008935 \%$ accuracy.

\section{Measuring apparatus for AE measurement}

For correct analysis and evaluation of acoustic parameters we used modular system Dakel. Before AE activity measurement in course of testing it is crucial to identify suitable configuration of apparatus for observed AE parameters with use of DaeMon software. For this reason, we conducted a set of Hsu-Nielsen pen tests. Subsequently adequate inputs were set for signal detection in this range. These parameters were configured into DaeMon software to enable correct recording of AE characteristics. AE was monitored continuously through the tensile test. System was calibrated to sampling frequency $4 \mathrm{MHz}$ and amplification $35 \mathrm{~dB}$ with Dakel pre-amp (Dakel, 2011).

In experiment we used two piezoelectric sensors MDK-13. Placement of sensors for tensile test is depicted on Fig. 1. Both channels were equipped with pre-amp with $35 \mathrm{~dB}$ gain and special low-frequency slot in Dakel XEDO analyser.

\section{RESULTS AND DISCUSSION}

Basic graphic output in experimental data analysis are measured load characteristics, i.e. dependency of applied tension $\sigma$ on shift $\varepsilon$. Significantly higher indicative value is presented in following graphic outputs.

Following overall graph also presents plotted response of given sample to applied mechanic load in form of typical AE events count (Prosser, 1998). Diagram thus represents continuous recording of $\mathrm{AE}$ events for target group of samples, detected in course of tensile load application. Based on acquired outputs it is possible to analyse precisely how given sample of composite structure is deformed and its behaviour influence on activity of detected AE signals (Zacal et al., 2017). AE signals were recorded with primary intention to discover the typical signals attributable to phenomena occurring in course of deterioration of a composite structure with certain fibre orientation, which could be used to describe the corresponding type of behaviour under persistent load. In course of tensile testing also stereoscopic method was employed, which uses the information obtained from composite surface and describes the possibilities of description of deformations extent. Entire sequence of examined pictures from measurement could be analysed frame-by-frame with colour scale. We can observe individual shifts on length axis in time. Typical deformation field in course of tensile loading, which could be identified based on elongation $\varepsilon$ [\%], shows 4 distinctive phases of development (Greenhalgh and Hiley, 2008). Based on their characteristics we could well distinguish deformation sub regions. Thresholds between phases could be characterized as:

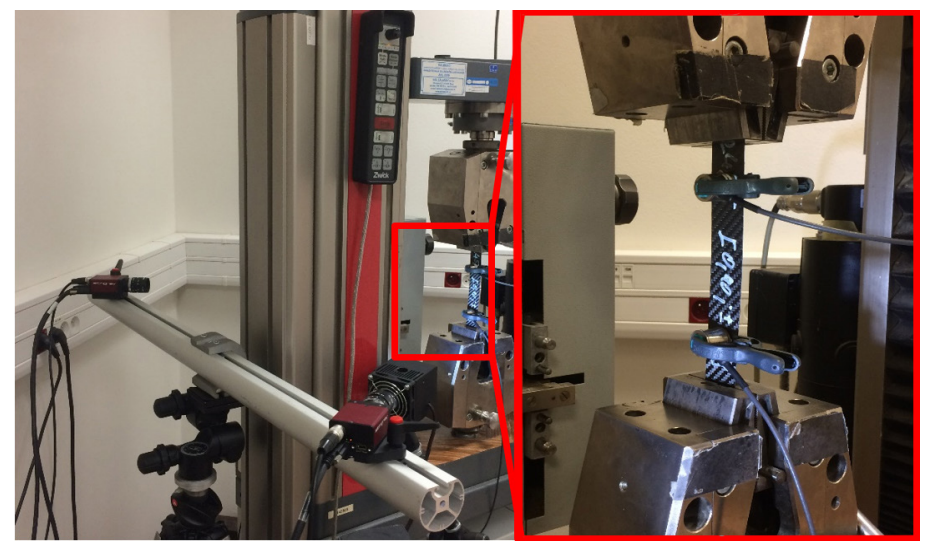

1: Experimental setup: left-optical stereovision system, right-location of AE sensor Author 
Phase I: Emergence of micro fissures in matrix

During the first phase the damage is represented above all by emergence of micro fissures in matrix. Overall damage is relatively minuscule in this phase and emerges at the beginning of elongation $\varepsilon$ of samples. Decrease in stiffness is less than $10 \%$ of original value and decrease in firmness is negligible.

\section{Phase II: Damage in matrix, separation of fibres from matrix}

Mechanisms of damage are strongly dependent on micro fissures in matrix, initiated in this phase. Fissures in matrix are present first in layers with $45^{\circ}$ and $90^{\circ}$ orientation. They are prominent in tensile loading. In continuous loading the fibre begins to deform differently from matrix and high levels of shear stress is generated on their interface.

\section{Phase III: Connection of fissures and onset of delamination}

Third phase consists namely of fissures clustering and local detrimentation along with onset of delamination. The damage evolves more slowly compared to Phase II. In response to increasing load tension the accumulation of tension occurs on the edge of matrix fissures and reinforcing fibres with $0^{\circ}$ orientation. It is caused by fissures in matrix ending on fibres with $90^{\circ}$ orientation. Consequently, the conditions for concentrated tension are set. As a result of these partial phenomena, the breakage of fibres occur in adjacent layers. Immense tensile stress occurs at the tips of matrix fissures and subsequently initializes late fissure dilatation in $0^{\circ}$ direction towards the fibres. This mechanism - called fissure group connecting - is essentially combination of matrix cracking and breakage of the axial fibre.

\section{Phase IV: Growth of delamination and fibre breaking}

In final phase IV (Fig. 3) the internal tension causes increase in intensity of damage mechanisms. Axial cracks grow, causing the isolation of fibres with $0^{\circ}$ orientation. This causes the gradual increase in delamination, which separates individual layers of laminate and series of individual components are created instead (maximum red areas on sample, Fig. 3). Subsequent reduction of firmness increases to the point of final collapse of entire structure.

Fig. 2 demonstrates a diagram of tension-deformation relationship and corresponding AE signals originating in tested composite material. In diagram the individual phases of optical measurement are also presented, which declare in which part the information acquired on the composite surface occur.

Fig. 3 demonstrates the comparison of stressed sample deformations. Maximum red coloured deformation signifies the greatest damage of

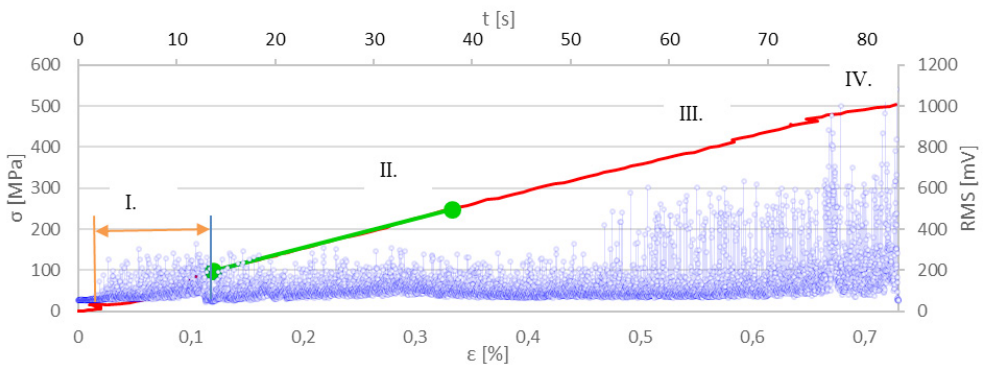

2: Typical diagram of tension-deformation with acoustic emission RMS of sample GG $245 \mathrm{~T} / \mathrm{GG} 630 \mathrm{~T}$ with orientation $\left[0^{\circ}, 90^{\circ}, 0^{\circ}, 90^{\circ}\right]$

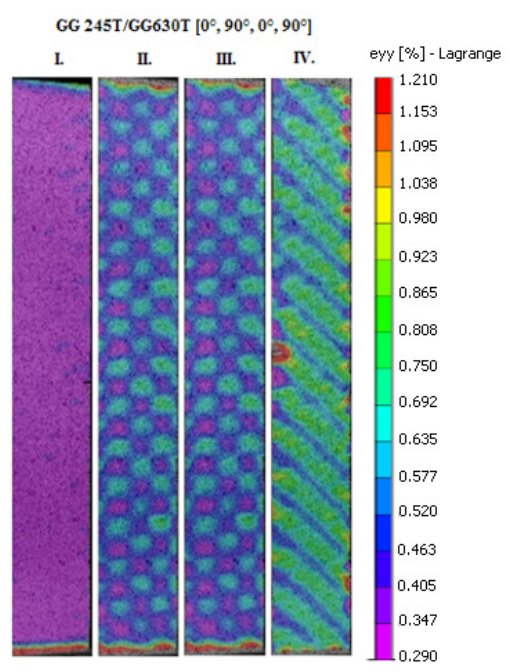

3: Deformation sub regions consisting of tension stress 
material, contrary to violet colour denoting the least deformation. It is visible, that in beginning ofload application the sample shows almost no deformation. In Phase II it is clearly visible, that fibres with $90^{\circ}$ orientation are subjected to higher stress (green hue), whereas $0^{\circ}$ fibres aren't subjected to such tension (marked in violet). In Phase III the tension concentrates and the colour pattern is checkered and more intense throughout the entire sample.

In Phase IV it is apparent how individual components of the composite subject to deformation and fibres with $90^{\circ}$ orientation on the edge of composite show the red colouring, which presents the highest flaw in material at this point (delamination). Due to formation of additional cracks in course of loading the shear stress is highest and clustered in superficial layers, which are aligned by $45^{\circ}$ with the direction of external tension. Fibres with $0^{\circ}$ orientation are subjected to highest tension and breaking of fibres along with pulling of fibres out of matrix takes place here.

In course of experiment the obtained values provide an effective mean to identify the diverse signals. It is suitable to subject these results to spectral analysis of measured signals, which could retrieve further important information on crack formation and its temporal development. Emergence of crack in mechanically stressed material is commonly incidental process. For description of incidental signals in frequency spectrum is commonly used power spectral density PSD, which is calculated from fast Fourier transformation (FFT) (Tůma et al., 1997).
In experimental measurements with XEDO system a large quantity of AE signals was sampled. Signal samples were processed with use of transformation into frequency spectrum and their maximum PSD values were analysed. In this phase of experiment evaluation only visual assessment of PSD function was conducted, with objective to distinguish at least the most significant phenomena occurring in experimental samples, and to establish the basic mapping of corresponding signal samples (Zacal et al., 2016). Following pictures show signal course and corresponding frequency analysis for each classified signal. Signal classified as fissures in matrix represents a failure characteristic with high signal intensity in lower frequency area, clearly visible in peak frequency (Fig. 4). Previous tests demonstrated, that the higher the angle between fibre orientation and applied load vector, the higher is also quantity of peak waves in signal. This is the case of classified matrix failure, because it is the prevailing wave regime in sample (Fig. 4).

In case of structural failure on interfacial contact surfaces of fibre $\times$ matrix this signal is characteristic with higher frequency (179 kHz), which is typical for this signal pattern (Fig. 5)

Frequency analysis of initiating delamination also reports a certain share of fibre oscillation. However, this is a classified signal characteristic with low intensity of higher vibrations (Fig. 6). This is attributable to weak interphasic interface in epoxide matrix.

Signals classified as breaking of fibres show minuscule duration time, which could be attributed

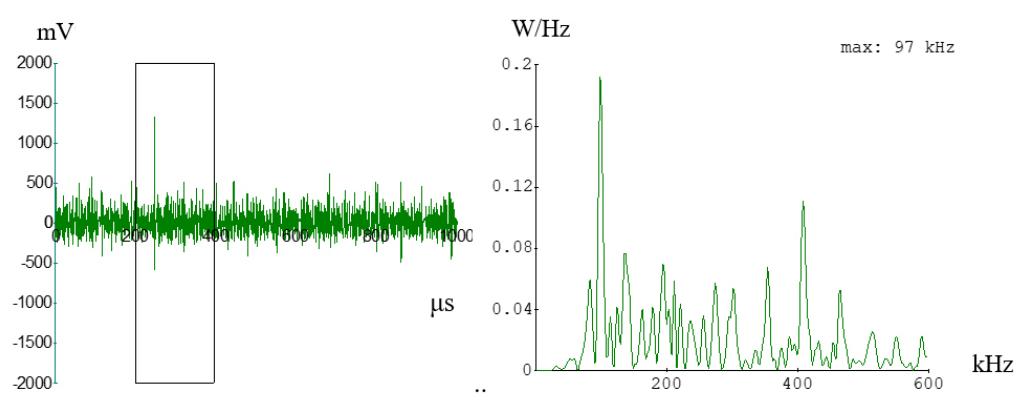

4: Oscilloscope and corresponding PSD function

Author

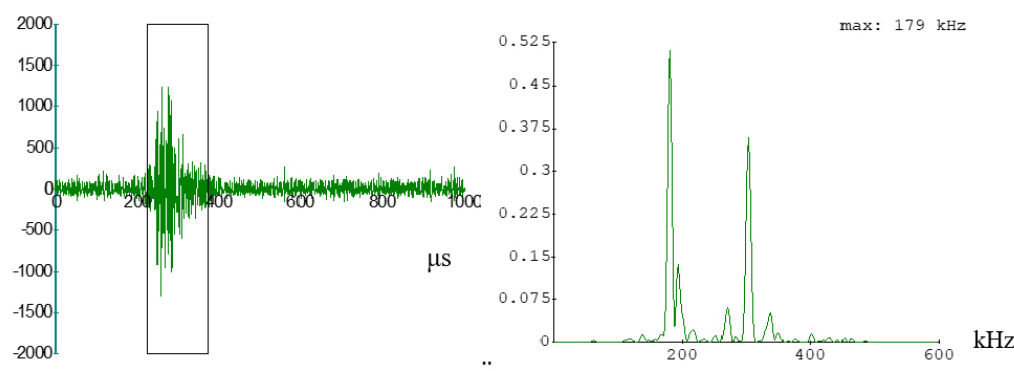

5: Fig. 5 Oscilloscope and corresponding PSD function

Author 
to short relaxation times. In comparison with matrix interface this signal is characteristic with very high frequency peak (Fig. 7).

Signals were identified as pulling the fibre off the matrix. They are characteristic with short duration. Maximum PSD for this AE events were reported around $670 \mathrm{kHz}$ (Fig. 8).

Study of signal sample recognition revealed that events discovered in peak frequency divisions are classified based on quantity and range of peak frequencies and frequency ranges defined above (Fig. 4-8). This part denotes the main parameters of $\mathrm{AE}$ signal, which is necessary for damage analysis in tested composites. For this purpose, the AE parameters were optimized for individual categories. This optimization enabled definition of crucial AE signal parameters and optimal count of categories. Sample recognition demonstrated existence of matching traits, which could be observed at frequency interface and which are linked to specific test characteristics used for classification of damage mechanisms. Analysis of individual areas reported that consistent events observed in each test occurred in peak frequency distributions. Peak frequency diagram was further analysed to establish the failure mechanism classification.

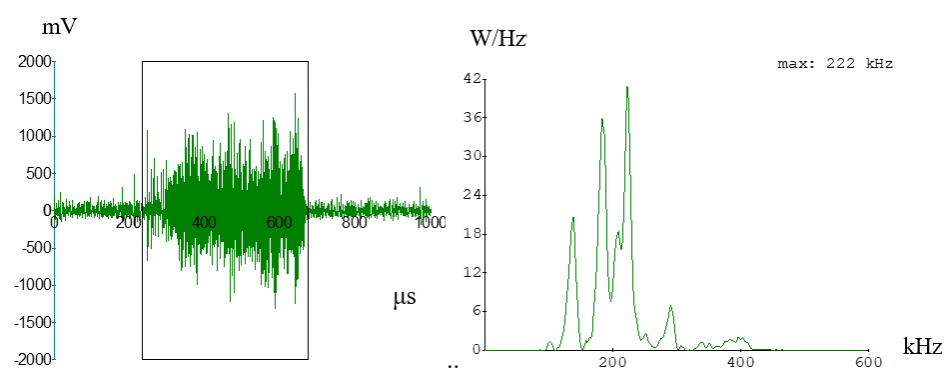

6: Oscilloscope and corresponding PSD function Author

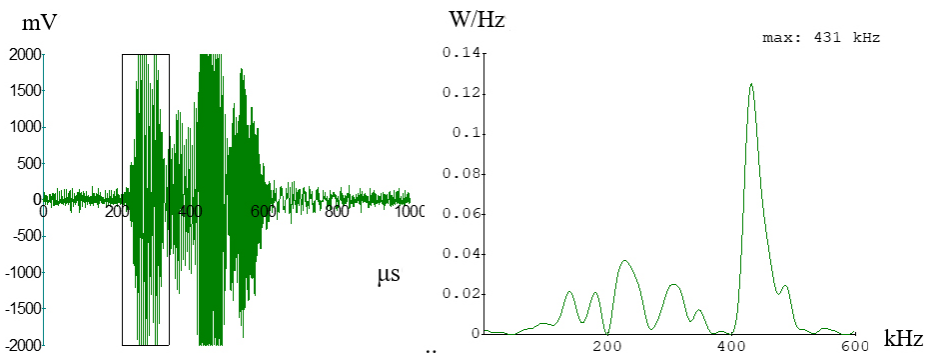

7: Oscilloscope and corresponding PSD functionn Author

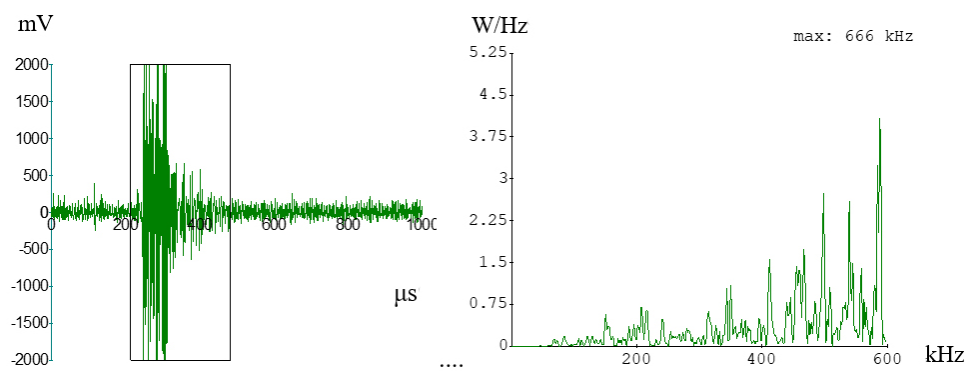

8: Oscilloscope and corresponding PSD function

Author

\section{CONCLUSION}

AE signals were gathered from extensive testing program, consisting of standard tensile tests of samples with carbon fibre orientation $\left[0^{\circ}, 90^{\circ}, 0^{\circ}, 90^{\circ}\right]$ for characterization of phenomena inside and between the cracking layers. Advantage of these sturdiness tests in tensile testing with use of AE is recognition of failure mechanisms both on surface and inside the material structure. Testing method provides the highest quality results and low computing requirements. In application of AE measurement, 


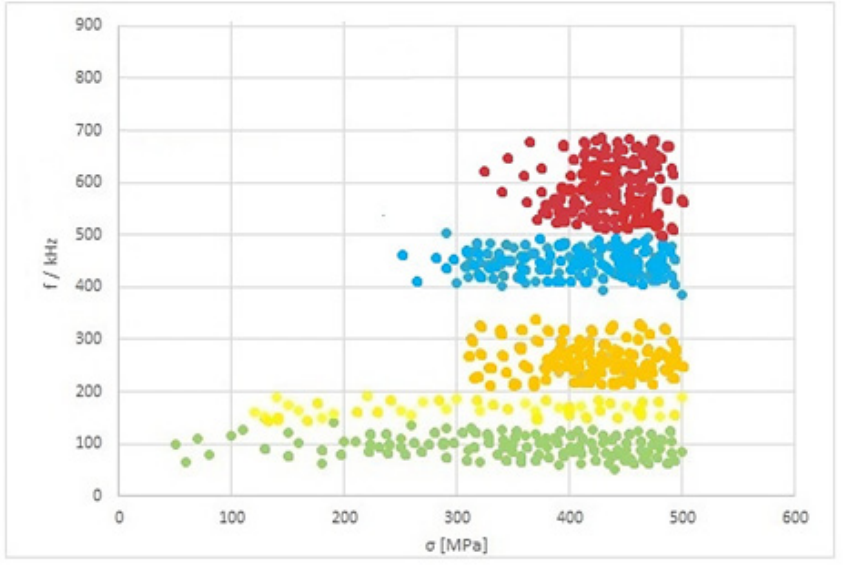

9: Frequency response of event typical for sample $\mathrm{GG} 245 \mathrm{~T} / \mathrm{GG} 630 \mathrm{~T}$ with orientation $\left[0^{\circ}, 90^{\circ}, 0^{\circ}, 90^{\circ}\right]$

we observed identified patterns with distribution of clustering peak frequencies. Frequency spectra mentioned above correspond to signal of individual tensile test in course of a single type composite material. First frequency area onsets with test start and its event count increases in characteristic points of initial fissure spreading. For these reasons the frequency area $\mathrm{fI}$ is most likely linked to emergence of micro-fissures in matrix. Second frequency area fII is connected to separation of fibres from matrix. Failure process in fIII area is delamination. Leading mechanism of delamination following cracking of matrix in $\mathrm{fI}$ and $\mathrm{fII}$ is fibre separation from matrix. From following frequency diagram, it is obvious that areas fIV and fV often start close to each other. This type of behaviour corresponds to chain of events detected in relation to delamination, fibre breaking and fibre extraction from the matrix. Frequency area fIII was thus attributed to delamination and therefore fIV and fV could be connected to fibre failure or fibre extraction out of matrix. Area fIV begins sooner and is attributed to fibre breaking, whereas $\mathrm{fV}$ area is linked to fibre extraction.

Definition of failure regimes in polymeric composites reinforced with carbon fibre with use of frequency content of acoustic emission presents a promising method for precise analysis of material structural characteristics. The results show that analysis of recorded AE impulses provides exact information on type and extent of damage in composite and therefore enable prediction of sample behaviour in course of load application. AE is recognized as a method providing information on structural state of material. Combined with stereovision analysis it discovers the location of possible structural failure. Subsequent Fourier transformation analysis supplements the acquired data with generalized characteristics of damage category. Combination of AE and stereoscopic analysis is regarded a suitable diagnostic tool for assessment of structural integrity of composite materials. In recent years the interest in "smart materials" is rising. Electric properties of carbon fibre composites were examined regarding their potential employment as smart materials. Use of electric properties for composite structure diagnostics is a promising area for future research. It is possible to manufacture carbon fibre composites with piezoelectric properties. Possibilities of affecting their firmness with electricity is a perspective area for basic research.

\section{Acknowledgements}

The research has been supported by the project TP 6/2017: Defectoscopic quality assessment of technical and organic materials; financed by IGA AF MENDELU.

\section{REFERENCES}

ABRY, J., CHOI, Y. CHATEAUMINOIS, A., DALLOZ, B., GIRAUD, G. and SALVIA, M. 2001. In-situ monitoring of damage in cfrp laminates by means of ac and dc measurements. Composites Science and Technology, 61(6): 855-864.

ANGELIDIS, N., WEI, C. and IRVING, P. 2004. The electrical resistance response of continuous carbon fibre composite laminates to mechanical strain. Composites Part A: Applied Science and Man-ufacturing (Incorporating Composites and Composites Manufacturing), 35(10): 1135-1147.

BAKER, C., MORSCHER, G. M., PUJAR, V. V. and LEMANSKI, J. R. 2015. Transverse crac-king in carbon fiber reinforced polymer composites: Modal acoustic emission and peak frequency analysis. Composites Science and Technology, 116:26-32.

DAKEL. 2011. Uživatelská dokumentace k programu Daemon. Praha: Zemědělské družstvo Rpety se sídlem ve Rpetech, Středisko technické diagnostiky DAKEL. 
DE GROOT, P. J., WIJNEN, P. A. M. and JANSSEN, B. F. R., 2000. Real-time frequency determina-tion of acoustic emission for different fracture mechanisms in carbon/epoxy composites. Com-posites Science and Technology, 55(4): 405-412.

DEPARTMENT OF DEFENSE. 2002. Composite Materials Handbook-Volume 1. Polymer Matrix Composites, Guidelines for Characterization of Structural Materials. [Online]. Fort Washington: Department of Defense. Available at: http://www.dtic.mil/dtic/tr/fulltext/u2/a426516.pdf [Accessed: 2018, July 15].

EHRENSTEIN, G. W. 2009. Polymerní kompozitní materiály. $1^{\text {st }}$ Edition. Praha: Nakl. Scientia.

GREENHALGH, E. S. and HILEY, M. J. 2008. Fractography of polymer composites: current status and future issues. In: Proceedings of the 13th European conference on composite materials (ECCM13). Stockholm: KTH Royal Institute of Technology.

GUTKIN, R., GREEN, C. J., VANGRATTANACHAI, S., PINHO, S. T., ROBINSON, P. and CURTIS, P. T. 2011. On acoustic emission for failure investigation in CFRP: Pattern reco-gnition and peak frequency analyses. Mechanical Systems and Signal Processing, 25(4): 1393-1407.

LU, C., DING, P. and CHEN, Z. 2011. Time-frequency analysis of acoustic emission signals generated by tension damage in CFRP. Procedia Engineering, 23: 210-215.

ONO, K. 2005. Current understanding of mechanisms of acoustic emission. The Journal of Strain Analysis for Engineering Design, 40(1): 1-15.

PLOTNIKOV, Y. A. and WINFREE, W. P. 1999. Visualization of subsurface defects in composites using a focal plane array infrared camera. In: Proceedings of SPIE - The International Society for Optical Engineering. Vol. 3700, pp. 26-31.

PROSSER, W. H. 1998. Waveform analysis of ae in composites. In: Proceedings of the Sixth International Symposium on Acoustics Emission from Composite Materials. Vol. 3700, pp. 61-70.

SCHINNER, G., BRANDT, J. and RICHTER, H. 1996. Recycling Carbon-Fiber-Reinforced Thermoplastic Composites. Journal of Thermoplastic Composite Materials, 9(3): 239-245.

TŮMA, J. et al. 1997. Zpracovani signali ziskanych z mechanických systemů užitim FFT. Praha: Sdělovací technika.

ÚNMZ. 1998. Plasty - Stanoveni tahových vlastností - Část 4: Zkušební podmínky pro izotropní a orthotropní plastové kompozity vyztuženévlákny. ČSN EN ISO 527-4. Praha: Úřad pro technickou normalizaci, metrologii a státní zkušebnictví.

ZAČAL, J., DOSTÁL, P., ŠUSTR M. and DOBROCKÝ, D. 2016. Monitoring of Changes Signal Acoustic Emission Signals Using Waveguides. Acta Universitatis Agriculturaeet Silviculturae Mendelianae Brunensis, 65(4): 1317-1322.

ZAČAL, J., DOSTÁL, P., ŠUSTR, M. and DOBROCKÝ, D. 2017. Acoustic Emission During Tensile Testing of Composite Materials. Acta Universitatis Agriculturae et Silviculturae Mendelianae Brunensis, 65(4): 1309-1315.

Jaroslav Začal: jaroslav.zacal@mendelu.cz

Contact information

Petr Dostál: petr.dostal@mendelu.cz

Jakub Rozlivka: jakub.rozlivka@mendelu.cz

Martin Brabec: martin.brabec@mendelu.cz 